\title{
Spatial access by public transport and likelihood of healthcare consultations at hospitals
}

\section{Boer Cui}

Department of Civil Engineering, McGill University

E-mail: boer.cui@,mail.mcgill.ca

\section{Geneviève Boisjoly}

Department of Civil, Geological and Mining Engineering, Polytechnique Montreal

E-mail: gboisjoly@polymtl.ca

\section{Rania Wasfi}

Centre de Recherche du CHUM, Université de Montréal

rania.wasfi@,crchum.qc.ca

\section{Heather Orpana}

Centre for Surveillance and Applied Research, Public Health Agency of Canada

heather.orpana@canada.ca

\section{Kevin Manaugh}

Department of Geography, McGill University

kevin.manaugh@mcgill.ca

\section{Ron Buliung}

Department of Geography and Planning, University of Toronto

ron.buliung@utoronto.ca

\section{Yan Kestens}

Centre de Recherche du CHUM, Université de Montréal

yan.kestens@,umontreal.ca

\section{Ahmed El-Geneidy \\ School of Urban Planning, McGill University \\ ahmed.elgeneidy@mcgill.ca}

July 2019

Word count: 6135 words text +3 tables $* 250$ words $=6885$ words

For Citation please use: Cui, B., Boisjoly, G., Wasfi, R., Orpana, H., Manaugh, K., Buliung, R., Kestens, Y., \& El-Geneidy A. (2020). Spatial access by public transport and likelihood of healthcare consultations at hospitals. Paper to be presented at the Transportation Research Board $99^{\text {th }}$ Annual Meeting. 


\section{ABSTRACT}

2 As healthcare is a right in Canada, analyzing the distribution of spatial access to medical 3 consultations, which are crucial for the prevention, diagnosis and early treatment of illnesses, is 4 fundamental to understanding health equity. Spatial accessibility is a factor that can influence 5 whether individuals can reasonably reach the services they seek or not. However, as an indicator 6 of potential access, it does not guarantee realized access due to predisposing and need factors. This 7 study examines the influence of spatial accessibility to hospitals on the likelihood of consulting 8 with a healthcare professional at a hospital in eight Canadian metropolitan regions while controlling for individual characteristics including need for care through multilevel regression modelling. Spatial accessibility was computed using the two-step floating catchment area (2SFCA) method. Self-reported consultations and socio-demographic characteristics were obtained from the Canadian Community Health Survey. We found that the likelihood of consultations did not differ by age nor sex but followed a positive household income gradient (high-income OR: 1.205 CI: 1.109-1.309; middle-income OR: 1.073 CI: 0.996-1.156; compared to low-income). Living in areas with higher spatial accessibility was significantly and positively linked to consultations (OR: 1.012 CI: 1.005-1.020), even after controlling for perceived health (OR: 0.526 CI: 0.491-0.563), chronic conditions (OR: $1.860 \mathrm{CI}: 1.747-1.981$ ) and having a regular doctor (OR: 1.251 CI: 1.116-1.402). Policies that may improve spatial accessibility to healthcare services should be considered as doing so may improve the ability of individuals to consult healthcare professionals, which could lead to better health outcomes.

Keywords: spatial accessibility, healthcare utilization, consultations 


\section{INTRODUCTION}

Healthcare utilization refers to the use of services by individuals to prevent and treat health problems, promote well-being or obtain information about one's health (1). Consulting with a healthcare professional is an important act of health-seeking individuals and can lead to better health outcomes as illnesses can be addressed at an earlier stage or be prevented altogether. To measure healthcare utilization, surveys are administered to the general public to collect selfreported information, an example being the Canadian Community Health Survey. Such surveys allow researchers to track the services that respondents report using over a period of time (e.g. the number of visits to the doctor's office).

The utilization of healthcare, according to the Healthcare Utilization Model (2), is affected by predisposing factors, enabling factors, and need. The enabling factors are the policies that are in place that allow individuals to access services. One of the major barriers of access, especially for vulnerable population (3), is the physical distance that separates individuals from the services that they seek, which on a macroscopic level, is the result of both the distribution of healthcare facilities throughout a region as well as the performance of the transport systems, where the level of service provided by the transport system has an impact on the ability of individuals to reach potential destinations within the cost threshold. This topic has been studied under the term of spatial accessibility and it can be measured in the healthcare context using the two-step floating catchment area (2SFCA) method which accounts for both capacity and demand, expressed through the service-to-population ratio, and whether individuals can realistically reach that particular service within a reasonable amount of time. The transport mode taken to access healthcare also strongly influences care utilization as research has shown that, compared to driving or being driven, those who use public transport are less likely to utilize healthcare services and unreliable or infrequent service has resulted in more instances of missed appointments (4). Nonetheless, it is generally found that disadvantaged groups in society rely more heavily on public transport to access services related to their daily needs, highlighting the importance of research on spatial accessibility by public transport.

While there have been numerous studies that make use of the 2SFCA method (5-7) to measure accessibility, few have used it to evaluate the effect of spatial accessibility on the realization of healthcare, specifically on health-seeking acts such as consultations. In this study, we examine the relationship between spatial accessibility to hospitals and the likelihood of consultations with a healthcare professional at a hospital using the 2SFCA method, using data obtained for eight Canadian metropolitan regions (Figure 1). Self-reported consultations as well as variables related to their predisposition and needs for healthcare are obtained from the Canadian Community Health Survey (CCHS). Multilevel regression is carried out to model the effect of spatial accessibility on the likelihood of consultations while controlling for predisposing factors (e.g. age, sex, and household size etc.) and healthcare needs of individuals (e.g. presence of chronic conditions and self-perceived health). This study contributes to the literature on healthcare utilization and whether an adequate bed-to-population ratio and good access to hospitals by public transport are positively associated with the likelihood of an individual consulting a healthcare professional 


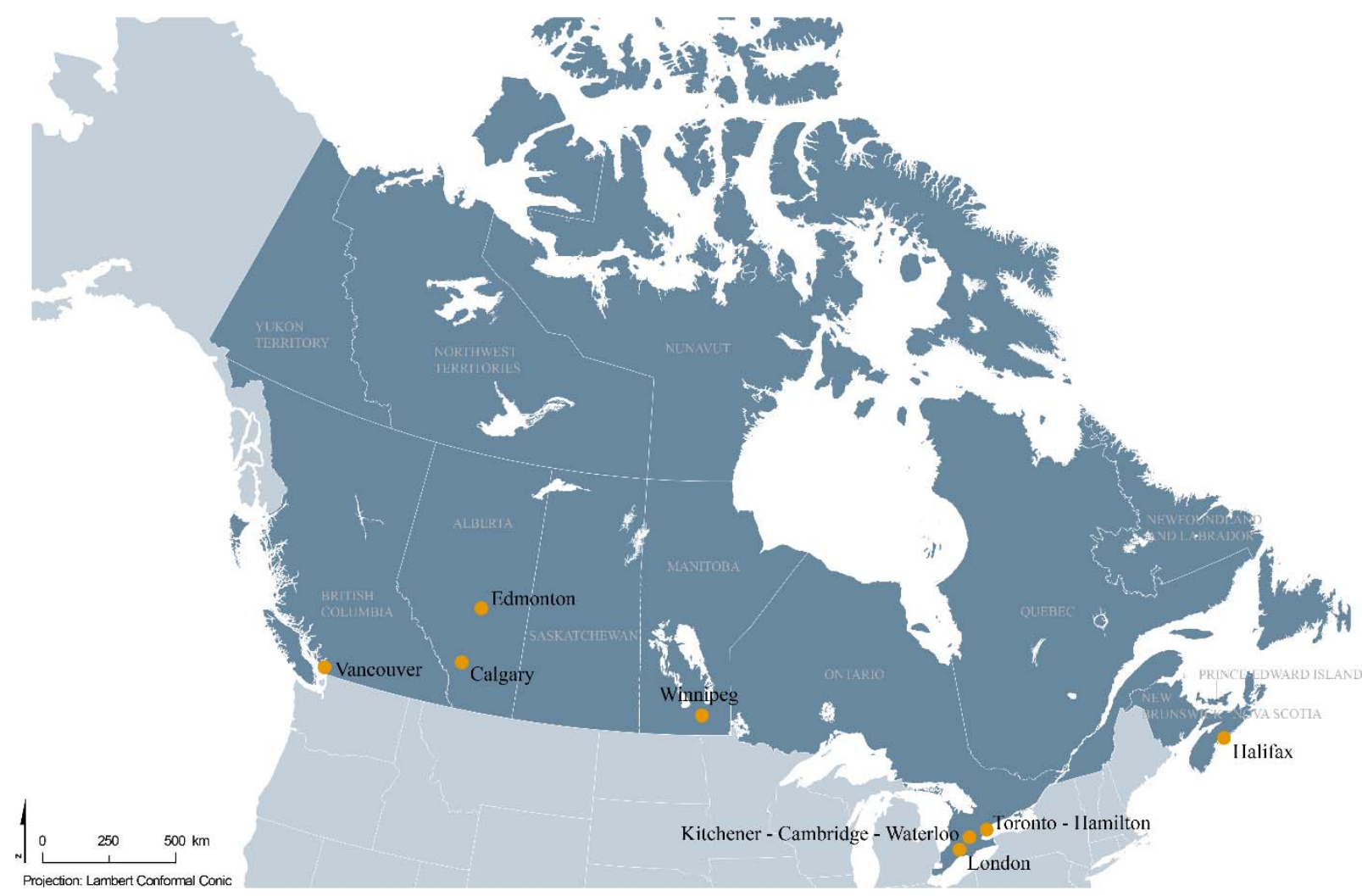

2 Figure 1 Context map of the eight metropolitan regions in the study

\section{LITERATURE REVIEW}

Health researchers have generally quantified spatial accessibility using relatively simple metrics such as the distance or time to the nearest service (8) or service-to-population ratios which measure the availability of the service once potential demand from the population is accounted for (9). At the same time, transport researchers quantify accessibility as the number of opportunities that can be reached from a point within a time threshold by a specific mode, e.g. number of hospitals that can be reached within 45 minutes by public transport, which is also referred to as cumulative accessibility (10). Other researchers have used gravity-based accessibility measures to account for the increased friction of distance associated with services that are located further away (11). However, cumulative measures are sometimes preferred for their ease of computation and interpretation while being highly correlated with gravity-based measures (12). Recent research has attempted to improve the measure of accessibility to incorporate variability in both the availability of opportunities at different times of the day (13) as well as availability of the transport system (14). However, Cui et al. (15) have shown that the use of more detailed data, which is time and resource-consuming to gather, does not always improve the evaluation of the impact of accessibility on various travel outcomes, such as commute duration and mode choice.

When used by themselves, these measures all have shortcomings: the service-to-population ratio does not consider whether an individual is able to realistically reach the healthcare service and is often calculated at aggregated spatial units too large to be meaningful (16); cumulative and gravity-based as well as distance to service measures do not consider the capacity of the service, i.e. the demand for access to one of 100 beds available at a hospital in a downtown centre is higher compared to one of 100 beds in a less dense suburban area. To address these shortcomings, researchers have developed the two-step floating catchment area (2SFCA) method $(5 ; 6)$ to control 
for travel impedance, capacity restrictions and competition effects (9). The 2SFCA method consists of two stages where the service-to-population ratio is first generated for each hospital and then accessibility to hospitals is generated where the service-to-population ratio for each hospital is summed for travel times less than the threshold travel time.

There is a significant body of empirical research quantifying spatial accessibility using the 2SFCA method (17-20). Some of this research aims to identify healthcare professional shortage areas using methods of spatial analysis (17) where others evaluate whether identified gaps are more pronounced for more disadvantaged groups in society $(19 ; 20)$. In addition, researchers have examined the spatial accessibility to healthcare by various modes and found that accessibility is greater by car than public transport and walking, implying that limited access to healthcare can also be due to lack of access to a personal vehicle, or to inefficiencies in public transport systems (18). In other words, transport can be a barrier for accessing healthcare, with some studies indicating that individuals living in rural regions have it worse (21).

Few studies have evaluated the degree to which spatial accessibility to healthcare influences reported healthcare utilization. Most studies use simple measures of spatial accessibility such as travel distance or time to the care facility $(8 ; 22 ; 23)$ which, as mentioned previously, do not account for demand. However, two similar studies $(24 ; 25)$ make use of the 2SFCA method with a gravity-based accessibility measure to evaluate the role of accessibility to healthcare on the odds of using emergency departments for primary care treatable conditions. In both studies, a lack of resources for primary care was linked to higher rates of preventable hospitalizations.

Aside from spatial access, the use of healthcare also depends on the predisposition of the individual to use services as well as their needs for care (2). Higher rates of consultation are observed for females $(26 ; 27)$ and between age groups, those at the extreme ends of the spectrum exhibit higher consultation rates (26). However, for both sex and age, the difference is minimized when the need for care is accounted for (28). Psychological and attitudinal factors such as perceived susceptibility and perceived costs and benefits from seeking medical care are examples of determinants reflecting the perceived need for care (29). A low perception of one's health is correlated with more consultations (30). In addition, individuals who have chronic conditions that necessitate regular check-ups are more likely to consult general practitioners $(26 ; 31)$; as are those who have a regular doctor whom they can visit easily $(27 ; 32)$. Furthermore, utilization patterns differ between income groups for different types of healthcare services, but findings are mixed. Low-income populations have sometimes been linked to lower levels of regular and chronic care service utilization Arcury et al. (21), and sometimes higher consultation rates for most types of services except for preventative services (26). This is consistent with other research indicating that preventive services are not delivered to those with the highest-risk (33).

\section{DATA AND METHODOLOGY}

\subsection{Consultation with healthcare professionals (outcome of interest)}

The dependent variable that we are concerned with is whether or not an individual, living in one of the eight Canadian metropolitan regions, has consulted a healthcare professional at a hospital. As consultations can be, in some cases, a voluntary act of health-seeking individuals as opposed to emergent care, it's more worthwhile to examine the impact of spatial accessibility on this type of healthcare service. This information was obtained from the 2012, 2013, and 2014 cycles of the annual component of the Canadian Community Health Survey (CCHS) collected by Statistics Canada. The CCHS is a national, cross-sectional survey that collects information related to the health status, healthcare utilization and health determinants for the Canadian population. Each 
cycle of the survey, which has been conducted annually since 2007, relies on a sample of 65,000 participants from all provinces and territories (although not all components of the survey are answered by respondents in all provinces and territories depending on the survey cycle). Sample respondents are selected from the household Canadian population 12 years of age and older with an exclusion rate of $3 \%$.

In the survey (where the wording was exactly the same for the three survey cycles that were used), a series of questions were asked regarding consultations with healthcare professionals. First, respondents were asked "[In the last 12 months,] have you seen, or talked to any of the following health professionals about your physical, emotional or mental health" with the healthcare professionals being: a) a family doctor or general practitioner (CHP_03), b) eye specialist (CHP_06), c) other medical doctor or specialist (CHP_08), d) nurse (CHP_11), and e) dentist, dental hygienist or orthodontist (CHP_14).

For each healthcare professional category, the respondents were then asked about the frequency of visit in the last 12 months. They were also asked about the location of the most recent contact (consultation) with a family doctor or general practitioner, another medical doctor or specialist, or a nurse. Since the accessibility data that we generated is to beds at a hospital, we consider a respondent as having consulted a healthcare professional at a hospital, if they have consulted with one of these healthcare professionals at a hospital (hospital emergency room or hospital outpatient clinic), as opposed to the other possible locations such as a doctor's office. A respondent observation was given a value of zero for the dependent variable if they did not consult these healthcare professionals or if they did not do so at a hospital.

For each respondent, their measured spatial accessibility (for the census tract of their residence) was matched using the postal code associated with each respondent against a vector data file containing the locations of postal code centroids to identify the census tract that each postal code is located within.

\subsection{Spatial accessibility to hospital-based healthcare services}

Three data inputs are required to generate accessibility measures to healthcare at the census tract level using the two-step floating catchment area (2SFCA) method: population, supply of healthcare services, and travel time by public transport between census tracts. Population data for each census tract was obtained from the 2016 Census. In this study, we define the supply of healthcare services to be the number of hospital beds staffed and in operation. This information was obtained through the Canadian Institute for Health Information (CIHI) for Canadian provinces in 2015-2016 (34) where the total number of beds associated with each hospital (including emergency rooms, outpatient clinics and specialized care) was provided and then geocoded using a Google API using the hospital name and address. Since this data was not available for Quebec (at the time of analysis), our geographic scope of analysis is limited to eight metropolitan regions, and does not include Ottawa-Gatineau, Montreal and Quebec City.

We decided to focus on hospitals as the healthcare service location of interest for two reasons: access to hospitals is generally less restricted across the country (e.g. physicians/family doctors can exercise discretion when choosing to take on patients so meaningful spatial access cannot be generated for these practices) and geographic access to these services implies longer travel distances which would require users to travel via motorized modes such as public transport. Furthermore, the specification of access to the number of beds available at each hospital captures the healthcare supply available to individuals and is a proxy for the level of service provided by the hospital (35). 
To compute travel time by public transport between census tracts, the General Transit Feed Specification (GTFS) data containing the scheduled service for May 2017 (or as close as possible to May 2017) was first obtained from the transport agencies operating in each of the metropolitan areas. Then, using the Add GTFS to a network dataset toolbox in ArcGIS, a joint network between public transport and streets was created which enabled computation of travel time matrices between all pairs of census tracts within each metropolitan region. The matrix was computed using fastest route calculations at 10 a.m. representing off-peak level of service on a regular Tuesday. The public transport travel time includes access, egress, waiting, in-vehicle, and transfer times as applicable.

The first step of the 2SFCA method is to generate the service to population ratio $V_{j}$ for each hospital using:

$$
V_{j}=\frac{s_{j}}{\sum_{k} P_{k} f\left(t_{k j}\right)} \text { and } \mathrm{f}\left(t_{k j}\right)=\left\{\begin{array}{l}
1 \text { if } t_{k j} \leq 45 \text { minutes } \\
0 \text { if } t_{k j}>45 \text { minutes }
\end{array}\right.
$$

Where $j$ denotes a hospital, $S_{j}$ represents the capacity of the hospital (number of beds), $P_{k}$ is the population in census tract $k$ and $t_{k j}$ is the travel time between census tract $k$ and hospital $j$. $P_{k} f\left(t_{k j}\right)$ can therefore be interpreted as the population at location $k$ that can reach the hospital within 45 minutes by transit, assuming on-board capacity is unrestrained.

Then, accessibility to healthcare services $A_{i}$ is computed by summing the service-topopulation ratios for the hospitals that can be reached from each census tract centroid within 45 minutes:

$$
A_{i}=\sum_{j} V_{j} \mathrm{f}\left(t_{j i}\right) \text { and } \mathrm{f}\left(t_{j i}\right)=\left\{\begin{array}{l}
1 \text { if } t_{j i} \leq 45 \text { minutes } \\
0 \text { if } t_{j i}>45 \text { minutes }
\end{array}\right.
$$

Where $i$ denotes a census tract, $V_{j}$ is the service-to-population ratio for hospital $j$, and $t_{j i}$ is the travel time between $j$ and $i$ via public transport. This measure indicates the number of beds that can be accessed within the threshold while accounting for the impact of competition as summarized by the service-to-population ratio. As specialized healthcare is typically provided at the metropolitan rather than the neighborhood level, the travel time threshold was selected to reflect regional accessibility where 45 minutes is commonly used in transport planning (36).

\subsection{Other covariates and model development}

In addition to the main outcome of interest (accessibility), covariates obtained from the CCHS for each respondent living in one of the eight metropolitan regions of interest included: sociodemographic characteristics; self-perceived health; the presence of chronic disease conditions and whether they lived in an urban or rural area (Table 1). In addition, the survey cycle years (Year) are also included in the model as dummy variables to control for temporal effects.

Multilevel mixed effects logit models, extensions of logit regressions to address variability at both the census tract and region level, were developed to determine the effects of spatial accessibility of the home census tract, mediated by various socio-demographic characteristics, on the likelihood of an individual consulting a healthcare professional at a hospital using information collected in eight metropolitan areas. A three-level multilevel model is appropriate for this study due to the innately hierarchical structure of the survey data for survey respondents located within different census tracts within different metropolitan regions. This type of model account for the variations that occur not only with respondents from the same census tract, but also between census tracts (Level 2) and between the metropolitan regions (Level 3) considered in the study. Furthermore, a bootstrap technique was employed to minimize the effects of sampling error that 
arise when the model is run only once. By drawing samples each with a size $\mathrm{n}$ out of $\mathrm{N}$ observations with replacement and then repeating the regression process 50 times, we ensure that the models have converged and that the significance and confidence intervals of the explanatory variables are representative of the data.

Various trials of multilevel mixed-effects logit regressions models were carried out to test the influence of the various socio-demographic variables. We found that the work status of the respondent and his/her personal education level are correlated with their household income level. As a result, variables related to the work status and personal educational level were removed from the final model. In addition, variables that were found to be insignificant (and did not upset model stability) as well those that did not improve model fit were removed from the final model. These variables include the number of children aged 5 or younger in the household and whether the respondent is a recent immigrant.

\section{RESULTS AND DISCUSSION}

\subsection{Descriptive analysis}

Descriptive statistics of the sample (the population that consulted with a healthcare professional at a hospital) were first conducted (Table 2) where a few trends can be observed. A greater percentage of respondents who live in very high access census tracts, are older than 64 , have four people living in the household, have no children aged 5 and or younger under and including the age of 5, are part-time workers, have household income less than $\$ 50,000 \mathrm{CAD}$, have a post-secondary education, have a negative perception of their health, have a chronic condition or have a regular doctor reported having consulted with a healthcare professional at a hospital. Interestingly, the difference in the percentage of females who consulted compared to males are minimal. However, the subsequent step of regression modelling would provide more accurate results on the influence of each of these variables on the likelihood of consultation, while controlling for the influence of all others. 
TABLE 1 Variables used from the 2012, 2013, and 2014 cycles of CCHS

\begin{tabular}{|c|c|c|c|}
\hline Variable & Description & Coding & Question in CCHS \\
\hline Access & $\begin{array}{l}\text { Accessibility to hospitals in } 45 \\
\text { minutes }\end{array}$ & $0 \ldots 99.975$ & $\mathrm{~N} / \mathrm{A}$ \\
\hline Age & Age of the respondent & $12, \ldots, 102$ & DHH_AGE \\
\hline HHsize & $\begin{array}{l}\text { Number of persons in the } \\
\text { household }\end{array}$ & $0, \ldots, 14$ & DHHDHSZ \\
\hline Sex & Sex of the respondent & $\begin{array}{l}1=\text { female } \\
0=\text { male }\end{array}$ & DHH_SEX \\
\hline HH5yr & $\begin{array}{l}\text { Number of children } 5 \text { years old or } \\
\text { younger in the household }\end{array}$ & $0, \ldots, 4$ & DHHDLE5 \\
\hline Work status & Work status of the respondent & $\begin{array}{l}1=\text { full-time } \\
0=\text { part-time }\end{array}$ & LBSDPFT \\
\hline $\begin{array}{l}\text { Recent } \\
\text { immigrant }\end{array}$ & $\begin{array}{l}\text { Whether the respondent } \\
\text { immigrated to Canada within } 5 \\
\text { years of the year of the survey }\end{array}$ & $\begin{array}{l}1=\text { recent immigrant } \\
0=\text { not recent immigrant }\end{array}$ & $\begin{array}{l}\text { Coded using } \\
\text { SDCFIMM }\end{array}$ \\
\hline HHincome & $\begin{array}{l}\text { Household income of the } \\
\text { respondent }\end{array}$ & $\begin{array}{l}1=\text { none to } \$ 49,999 \\
2=\$ 50,000 \text { to } \$ 99,999 \\
3=\text { more than } \$ 100,000\end{array}$ & $\begin{array}{l}\text { Coded using } \\
\text { INCDHH }\end{array}$ \\
\hline Pers. Edu. & $\begin{array}{l}\text { Highest education level of the } \\
\text { respondent }\end{array}$ & $\begin{array}{l}1=\text { Less than secondary } \\
2=\text { secondary } \\
3=\text { post-secondary }\end{array}$ & $\begin{array}{l}\text { Coded using } \\
\text { EDUDR04 }\end{array}$ \\
\hline Pos. Health & $\begin{array}{l}\text { Whether the respondent has a } \\
\text { positive perception of his/her } \\
\text { general health }\end{array}$ & $\begin{array}{l}1=\text { good, very good, } \\
\text { excellent } \\
0=\text { poor, fair }\end{array}$ & $\begin{array}{l}\text { Coded using } \\
\text { GENDHDI }\end{array}$ \\
\hline Chronic & $\begin{array}{l}\text { Whether the respondent has a } \\
\text { chronic condition* }\end{array}$ & $\begin{array}{l}1=\text { has a chronic } \\
\text { condition } \\
0=\text { does not have a } \\
\text { chronic condition }\end{array}$ & $\begin{array}{l}\text { CCC_031- } \\
\text { CCC_290 }\end{array}$ \\
\hline Regular Doc & $\begin{array}{l}\text { Whether the respondent has a } \\
\text { regular medical doctor }\end{array}$ & $\begin{array}{l}1=\text { has a regular doctor } \\
0=\text { does not have a } \\
\text { regular doctor }\end{array}$ & HCU_1AA \\
\hline
\end{tabular}

*Chronic conditions include asthma, arthritis, back problems, high blood pressure, migraine headaches, COPD, diabetes, heart disease, cancer, stomach or intestinal ulcers, effects of stroke, urinary incontinence, bowel disorder, Alzheimer's disease or dementia, mood disorder, anxiety disorder, fibromyalgia (2013 \& 2014), scoliosis (2013 \& 2014), chronic fatigue (2013 \& 2014), and chemical sensitivities ( $2013 \& 2014)$ 
1 TABLE 2 Descriptive statistics of the population that consulted with a healthcare 2 professional at a hospital in past 12 months, CCHS 2012, 2013, and 2014 cycles

\begin{tabular}{|c|c|c|c|}
\hline & Variable & Observations & Consulted a professional at a hospital (\%) \\
\hline Access & $\begin{array}{l}<45^{\text {th }} \text { percentile } \\
45^{\text {th }} \text { to } 90^{\text {th }} \text { percentile } \\
>90^{\text {th }} \text { percentile }\end{array}$ & $\begin{array}{c}26,589 \\
27,524 \\
5,645\end{array}$ & $\begin{array}{r}12.5 \\
12.4 \\
14.3\end{array}$ \\
\hline Year & $\begin{array}{l}2012 \\
2013 \\
2014\end{array}$ & $\begin{array}{l}14,630 \\
15,100 \\
30,028\end{array}$ & $\begin{array}{l}12.2 \\
12.3 \\
13.0\end{array}$ \\
\hline Age category & $\begin{array}{l}12-17 \\
18-24 \\
25-64 \\
65+\end{array}$ & $\begin{array}{c}464 \\
4,657 \\
31,960 \\
16,099\end{array}$ & $\begin{array}{c}9.7 \\
9.9 \\
12.1 \\
15.6\end{array}$ \\
\hline $\begin{array}{l}\text { HHsize } \\
\text { category }\end{array}$ & $\begin{array}{l}1 \\
2 \\
3 \\
4 \\
5+\end{array}$ & $\begin{array}{c}15,277 \\
20,300 \\
9,149 \\
9,730 \\
5,302\end{array}$ & $\begin{array}{l}12.8 \\
12.4 \\
13.8 \\
14.5 \\
11.7\end{array}$ \\
\hline Sex & $\begin{array}{l}\text { Female } \\
\text { Male }\end{array}$ & $\begin{array}{l}33,002 \\
26,756\end{array}$ & $\begin{array}{l}9.6 \\
9.4\end{array}$ \\
\hline $\begin{array}{l}\text { HH5yr } \\
\text { category }\end{array}$ & $\begin{array}{l}0 \\
1 \\
2 \\
3+\end{array}$ & $\begin{array}{c}53,301 \\
4,497 \\
1,748 \\
212\end{array}$ & $\begin{array}{c}12.9 \\
10.8 \\
8.5 \\
10.4\end{array}$ \\
\hline Work status & $\begin{array}{l}\text { Full-time } \\
\text { Part-time }\end{array}$ & $\begin{array}{c}24,340 \\
6,026\end{array}$ & $\begin{array}{l}11.0 \\
12.5\end{array}$ \\
\hline $\begin{array}{l}\text { Recent } \\
\text { immigrant }\end{array}$ & $\begin{array}{l}\text { Yes } \\
\text { No }\end{array}$ & $\begin{array}{c}1,982 \\
15,847\end{array}$ & $\begin{array}{c}6.9 \\
11.2\end{array}$ \\
\hline $\begin{array}{l}\text { HHincome } \\
\text { category }\end{array}$ & $\begin{array}{l}0 \text { to } 49,999 \\
50,000 \text { to } 99,999 \\
>100,000\end{array}$ & $\begin{array}{l}21,440 \\
19,969 \\
18,349\end{array}$ & $\begin{array}{l}13.4 \\
12.1 \\
12.2\end{array}$ \\
\hline Pers. Edu. & $\begin{array}{l}<\text { Secondary } \\
\text { Secondary } \\
\text { Post-secondary }\end{array}$ & $\begin{array}{l}11,367 \\
14,158 \\
32,995\end{array}$ & $\begin{array}{l}11.4 \\
12.5 \\
13.1\end{array}$ \\
\hline Pos. Health & $\begin{array}{l}\text { Yes } \\
\text { No }\end{array}$ & $\begin{array}{c}52,150 \\
7,491\end{array}$ & $\begin{array}{l}11.1 \\
24.4\end{array}$ \\
\hline Chronic & $\begin{array}{l}\text { Yes } \\
\text { No }\end{array}$ & $\begin{array}{l}35,361 \\
24,397\end{array}$ & $\begin{array}{c}16.3 \\
7.7\end{array}$ \\
\hline Regular Doc & $\begin{array}{l}\text { Yes } \\
\text { No }\end{array}$ & $\begin{array}{c}54,513 \\
5,185\end{array}$ & $\begin{array}{c}13.0 \\
8.8\end{array}$ \\
\hline
\end{tabular}




\subsection{Statistical analysis}

The aim of this paper is to understand the relationship between accessibility by public transport to hospitals and the likelihood of consultations with a healthcare professional within these hospitals. Results of the multilevel logit regression (Table 3) show that living in a census tract with higher spatial accessibility increased an individual's odds of consultation with a healthcare professional at a hospital, while controlling for predisposing and need factors. Specifically, we found that a one unit increase in accessibility (one additional bed/1000 individuals) is associated with an increased likelihood of hospital consultation of $1.2 \%$.

This result has two implications for professionals. The availability of healthcare services, measured using a service-to-population ratio, considers the balance between supply of services and potential competition between users. In other words, either the supply of services at the hospitals (proxied by the number of beds) or the demand from individuals within reach of the hospital can be managed. On the supply side, an increase in the number of beds or variety of services at hospitals can be beneficial to improve the consultation rates of health-seeking individuals. On the demand side, while it is undesirable to reduce competition for these services by limiting certain individuals' access to them, measures can be taken to manage the demand. For example, healthcare service providers can ensure that individuals are informed of the availability of beds or services at all nearby hospitals to distribute demand more appropriately.

On the other hand, adequate access to healthcare is also dependent on the quality of the transport system. As planners advocate for the use of public transport as opposed to private vehicles, it is important to consider its implications on access to healthcare and subsequent impacts on individuals' health outcomes. When public transport is unreliable or infrequent, (37) this makes it difficult for users to reach facilities on time for appointments or treatments. This issue is particularly evident for those who are older or have lower income and therefore less likely to have access to a personal vehicle. Therefore, improvements in transport services may be a way to improving public transport accessibility. As well, it is important to recognize healthcare facilities as key destinations to be connected to the existing system when planning for system expansions in order to improve access to these facilities.

Regarding the predisposing and need factors, we found that older individuals were not more likely to consult (based on a linear relationship) despite results from the summary statistics shown in Table 2. This finding has been observed by Nabalamba and Millar (27) as well where they cite that this is perhaps due to the inclusion of other factors in the model that better address the need for consultations like the presence of chronic conditions which are more prevalent in older individuals. We also found that females were not more likely than males to consult and this finding has been attributed to the inclusion of need-based factors a well where researchers found that after accounting for medications for common morbidities, the difference between the consultation rates of the two sexes diminish (28). In addition, it is possible that by limiting the location of consultations in the present study to hospitals could have impacted these results.

Moreover, the likelihood of consultation did differ between income groups and a consultation gradient was observed where, compared to the low-income, the middle- and highincome households, were more likely to consult for healthcare although the difference was less pronounced for middle-income households. This finding has been previously observed as well (27). While this is contrary to what was observed in Table 2, this may demonstrate that there are additional factors at play that when controlled for, decrease the likelihood of consulting for the low-income group. In addition, household size has a negative impact on consultations where an increase of one additional person decreases the likelihood of consultation by $4.7 \%$. As expected, having a positive perception of one's health status decreases the likelihood of consultation 
significantly by around $50 \%$ whereas the presence of a chronic condition greatly increases the likelihood of consultations by $86 \%$. Lastly, having a regular doctor increases the likelihood of consultations at a hospital by $25 \%$ as individuals with regular doctors are more likely to have more health problems (27), so even if they have a family doctor as their regular doctor, they would be more likely to visit a hospital for a consultation with a specialist or other professional other than their regular doctor. Note that the survey year did not affect the likelihood of consultation and these cycle variables were dropped from the final model output.

TABLE 3 Results of multilevel mixed-effects logit regression model

\begin{tabular}{|c|c|c|c|c|}
\hline Variable & \multicolumn{2}{|c|}{ Odds Ratio } & \multicolumn{2}{|c|}{$95 \% \mathrm{CI}$} \\
\hline Access & 1.012 & $* * *$ & 1.005 & 1.020 \\
\hline Age & 0.999 & & 0.998 & 1.001 \\
\hline HHsize & 0.953 & $* * *$ & 0.929 & 0.978 \\
\hline Sex $($ ref. $=$ male $)$ & 0.973 & & 0.919 & 1.030 \\
\hline HHincome (ref. = low) & & & & \\
\hline Middle & 1.073 & $*$ & 0.996 & 1.156 \\
\hline High & 1.205 & $* * *$ & 1.109 & 1.309 \\
\hline Pos. Health (ref. = negative) & 0.526 & $* * *$ & 0.491 & 0.563 \\
\hline Chronic $($ ref. $=$ no $)$ & 1.860 & $* * *$ & 1.747 & 1.981 \\
\hline Regular Doc (ref. $=$ no) & 1.251 & $* * *$ & 1.116 & 1.402 \\
\hline Constant & 0.109 & $* * *$ & 0.089 & 0.132 \\
\hline
\end{tabular}

No. of observations

Log likelihood

$\mathrm{AIC} \mid \mathrm{BIC}$

\begin{tabular}{c|cc|cc} 
AIC | BIC & \multicolumn{3}{c}{$40365.82 \mid 40491.75$} \\
\hline Intraclass correlation & Estimate & Std. Err. & \multicolumn{2}{c}{$95 \%$ CI } \\
ctuid & $3.21 \mathrm{E}-33$ & $4.43 \mathrm{E}-18$ &. & 0.090 \\
cma|ctuid & 0.077 & 0.006 & 0.066 & \multicolumn{2}{c}{$95 \% \mathrm{CI}^{\dagger}$} \\
Random-effects parameters & Estimate & Std. Err. $^{\dagger}$ & \multicolumn{2}{c}{.} \\
Var. of level two intercept & $1.15 \mathrm{E}-32$ & 0.122 &. & 0.706 \\
\hline
\end{tabular}

$* \mathrm{p}<0.05 * * \mathrm{p}<0.01 \quad * * * \mathrm{p}<0.001$

${ }^{\dagger}$ Bootstrapped standard error and confidence interval

\section{CONCLUSION}

This study examines the association of spatial accessibility to hospitals by public transport with the likelihood of the last medical consultation with a medical doctor or nurse at a hospital using data for eight Canadian metropolitan regions. We used the preferred method for measuring spatial accessibility - the two-step floating catchment area (2SFCA) method - to account for both the supply and demand for healthcare as quantified by the service-to-population ratio and the performance of the public transport system. A multi-level logit regression model was then developed to estimate the impact of accessibility, while controlling for factors reflecting the individual predisposition to seek healthcare and the need for care, on the likelihood of hospital consultations. Self-reported consultations and socio-demographic information were obtained from 
multiple cycles of the Canadian Community Health Survey (CCHS) for respondents residing in the eight metropolitan regions.

This study confirms that spatial accessibility was positively associated with the likelihood of consultations where an one unit (one bed/1000 individuals) increase in accessibility correlated to a $1.2 \%$ increase in the likelihood of an individual consulting a healthcare professional at a hospital, after controlling for the effects of other determinants of healthcare utilization related to individual characteristics and their need for healthcare. We also observed a positive income gradient. Age and sex were not significant variables, as observed in other studies when the need for healthcare, whether perceived or real, are accounted for. Regarding need, a positive perception of health, the existence of chronic conditions and access to a regular doctor were strong predictors of hospital consultations.

However, there is potentially still a disconnect between spatial accessibility and healthcare utilization as individuals may not be aware of their actual spatial accessibility and, for various reasons, have a different perception of the accessibility of their home location to healthcare than the one that can be measured. As mentioned in Section 2, researchers can obtain information about individual's perceived access to healthcare using surveys that are specific to this topic. Future studies should capitalize on this information to examine whether measured spatial accessibility (e.g. computed using the 2SFCA method) corresponds with individuals' perceptions of accessibility. If there is a significant mismatch between the two, further improvements to improve their objective spatial access may not necessarily be effective and more analysis is needed to decipher the real reasons for the perceived barrier when there isn't one.

There are certain limitations associated with the data and methodologies employed in this study. While we considered accessibility to hospitals at $10 \mathrm{a} . \mathrm{m}$. when public transport is operating at a lower level of service to reflect a more realistic view of the behavior of health-seeking individuals who may schedule non-emergent appointments at off-peak times, it may be valuable to examine the impact of accessibility on utilization at different times of day, including at night. In addition, a squared age variable should be incorporated in the model to demonstrate the potential difference between the consultation likelihood for very young and very old individuals. As well, the interaction between the socio-demographic variables and accessibility can be examined further in the model to reveal additional changes in the income gradient. Also, while consultations do occur frequently at hospitals, it may be even more valuable to examine whether spatial accessibility to other facilities for consultations including doctor's offices and clinics has a different effect on the likelihood of consultations. In addition, the use of hospital beds to reflect the capacity of hospitals may not be completely suitable when examining the likelihood of consultations where beds are not necessarily needed. However, information about more relevant indicators such as the number of doctors or services available were not available to us but would be useful in future studies. Lastly, it is important to note that the CCHS does not specify the type of consultation that was done but this information would be useful for future studies to reveal additional socio-demographic differences, particularly between sexes and age groups, on the likelihood of consultations for different purposes.

This research demonstrates the important role that spatial accessibility plays to enable individuals to access healthcare services. Particularly, better spatial accessibility to hospitals may lead to higher rates of healthcare consultations and this could have far-reaching implications for public health: as more individuals, particularly those with chronic health conditions or with higher needs for care, are able to consult healthcare professionals, it may be more likely that illnesses can be addressed early on to improve overall quality of life and to alleviate stress on the healthcare system. At the same time, it is unlikely that increased spatial accessibility would induce 
unnecessary trips as the impact of perceived health is a stronger determinant of consultations in the context of this study. Moreover, more equitable spatial accessibility could be a mechanism to reduce disparities in health between advantaged and disadvantaged groups.

\section{ACKNOWLEDGEMENTS}

This study was conducted with the financial support of the Canadian Social Sciences and Humanities Research Council. This research was also supported by funds to the Canadian Research Data Centre Network (CRDCN) from the Social Sciences and Humanities Research Council (SSHRC), the Canadian Institute for Health Research (CIHR), the Canadian Foundation for Innovation (CFI), and Statistics Canada. Although the research and analysis are based on data from Statistic Canada, the opinions expressed do not represent the views of Statistics Canada. The authors would like to thank the McGill-Concordia Laboratory of the Quebec Inter-University Centre for Social Statistics (QICSS) for providing the microdata for the Canadian Community Health Survey. The authors would also like to thank Robbin Deboosere for generating the public transport travel time matrix.

\section{AUTHORS CONTRIBUTIONS}

The authors confirm contribution to the paper as follows: study conception and design: Boisjoly, Wasfi, Orpana, Manaugh, Buliung, Kestens, \& El-Geneidy; data collection: Cui, Boisjoly, Wasfi, Orpana, Kestens, \& El-Geneidy; analysis and interpretation of results: Cui, Boisjoly, Wasfi \& ElGeneidy; draft manuscript preparation Cui, Wasfi, Orpana, Manaugh, Buliung, Kestens, \& ElGeneidy. All authors reviewed the results and approved the final version of the manuscript.

\section{REFERENCES}

[1] Carrasquillo, O. Health Care Utilization.In Encyclopedia of Behavioral Medicine, Springer, New York, NY, 2013.

[2] Andersen, R. A behavioral model of families' use of health services. Center for Health Adminstration Studies, University of Chicago, Chicago, IL, 1968.

[3] Williamson, D., M. Stewart, K. Hayward, N. Letourneau, E. Makwarimba, J. Masuda, K. Raine, L. Reutter, I. Rootman, and D. Wilson. Low-income Canadians' experiences with health-related services: implications for health care reform. Health Policy, Vol. 76, No. 1, 2006, pp. 106-121. [4] Silver, D., J. Blustein, and B. Weitzman. Transportation to clinic: Findings from a pilot clinicbased survey of low-income suburbanites. Journal of Immigrant and Minority Health/Center for Minority Public Health, Vol. 14, No. 2, 2012, pp. 350-355.

[5] Joseph, A. E., and P. R. Bantock. Measuring potential physical accessibility to general practitioners in rural areas: A method and case study. Social Science and Medicine, Vol. 16, 1982, pp. $85-90$.

[6] Luo, W., and F. Wang. Measures of spatial accessibility to health care in a GIS environment: synthesis and a case study in the Chicago region. Environment and Planning B: Planning and Design, Vol. 30, 2003, pp. 865 - 884.

[7] McGrail, M. R., and J. S. Humphreys. Measuring spatial accessibility to primary care in rural areas: Improving the effectiveness of the two-step floating catchment area method. Applied Geography, Vol. 29, 2009, pp. $533-541$.

[8] Goodman, D., E. Fisher, T. Stukel, and C. Chang. The distance to community medical care and the likelihood of hospitalization: is closer always better? American Journal of Public Health, Vol. 87, No. 7, 1997, pp. 1144-1150. 
[9] Neutens, T. Accessibility, equity and health care: Review and research directions for transport geographers. Journal of Transport Geography, Vol. 43, 2015, pp. 14 - 27.

[10] Wickstrom, G. Defining balanced transportation: A question of opprtunity. Traffic Quarterly, Vol. 25, No. 3, 1971, pp. 337-349.

[11] Weibull, J. An axiomatic approach to the measurement of accessibility. Regional Science and Urban Economics, Vol. 6, 1976, pp. 357 - 379.

[12] El-Geneidy, A., and D. Levinson. Access to Destinations: Development of Accessibility Measures. University of Minnesota Digital Conservancy, Minneapolis, MN. http://hdl.handle.net/11299/638.

[13] Boisjoly, G., and A. El-Geneidy. Daily fluctuations in transit and jobs availability: A comparative assessment of time-sensitive accessibility measures. Journal of Transport Geography, Vol. 52, 2016, pp. 73-81.

[14] Stepniak, M., J. Pritchard, and K. Geurs. The impact of temporal resolution on public transport accessibility measurement: Review and case study in Poland. Journal of Transport Geography, Vol. 75, 2019, pp. 8-24.

[15] Cui, B., E. Grise, A. Stewart, and A. El-Geneidy. Measuring the added effectiveness of using detailed spatial and temporal data in generating accessibility measures. Transport Findings, 2019. [16] Guagliardo, M. F. Spatial accessibility of primary care: concepts, methods and challenges. International Journal of Health Geographics, Vol. 3, No. 3, 2004.

[17] Luo, W. Using a GIS-based floating catchment method to assess areas with shortage of physicians. Health \& Place, Vol. 10, No. 1, 2004, pp. 1-11.

[18] Khakh, A., V. Fast, and R. Shahid. Spatial accessibility to primary healthcare services by multimodal means of travel: Synthesis and case study in the City of Calgary. International journal of environmental research and public health, Vol. 16, No. 2, 2019, p. E170.

[19] Bissonnette, L., K. Wilson, S. Bell, and T. I. Shah. Neighbourhoods and potential access to health care: The role of spatial and aspatial factors. Health \& Place, Vol. 18, 2012, pp. 841 - 853. [20] Shah, T. I., S. Bell, and K. Wilson. Spatial accessibility to health care services: Identifying under-serviced neighbourhoods in Canadian urban areas PLoS ONE, Vol. 11, No. 12, 2016, p. 0168208.

[21] Arcury, T., J. Preisser, W. Gesler, and J. Power. Access to transportation and health care utilization in a rural region. Journal of Rural Health, Vol. 21, No. 1, 2006, pp. 31-38.

[22] Al-Taiar, A., A. Clark, J. Longenecker, and C. Whitty. Physical accessibility and utilization of health services in Yemen. International Journal of Health Geographics, Vol. 9, No. 1, 2010, p. 38.

[23] Stentzel, U., J. Bahr, D. Fredrich, J. Piegsa, W. Hoffmann, and N. van den Berg. Is there an association between spatial accessibility of outpatient care and utilization? Analysis of gynecological and general care. BMC Health Services Research, Vol. 18, No. 1, 2018, p. 322.

[24] Fishman, J., S. McLafferty, and W. Galanter. Does spatial access to primary care affect emergency department utilization for nonemergent conditions? Health Services Research, Vol. 53, No. 1, 2016, pp. 489-508.

[25] Huang, Y., P. Meyer, and L. Jin. Neighborhood socioeconomic characteristics, healthcare spatial access, and emergency department visits for ambulatory care sensitive conditions for elderly. Preventive Medicine Reports, Vol. 12, 2018, pp. 101-105.

[26] Carr-Hill, R., N. Rice, and M. Roland. Socioeconomic determinants of rates ofconsultation in general practice based on fourth national morbidity survey ofgeneralpractices. British Medical Journal, Vol. 312, No. 7037, 1996, pp. 1008-1012. 
[27] Nabalamba, A., and W. Millar. Going to the doctor. Health Reports, Vol. 18, No. 1, 2007, pp. 23-35.

[28] Wang, Y., K. Hunt, I. Nazareth, N. Freemantle, and I. Petersen. Do men consult less than women? An analysis of routinely collected UK general practice data. BMJ Open, Vol. 3, 2013, p. 003320.

[29] Campbell, S., and M. Roland. Why do people consult the doctor? Family Practice, Vol. 13, No. 1, 1996, pp. 75-83.

[30] Kapur, N., I. Hunt, M. Lunt, J. McBeth, F. Creed, and G. Macfarlane. Psychosocial and illness related predictors of consultation rates in primary care - a cohort study. Psychological Medicine, Vol. 34, 2004, pp. 719-728.

[31] Andersson, H., G. Ejlertsson, I. Leden, and B. Schersten. Impact of chronic pain on health care seeking, self care, and medication: Results from a population-based Swedish study. Journal of Epidemiol Community Health, Vol. 53, No. 8, 1999, pp. 503-509.

[32] Xu, K. Usual source of care in preventive service use: A regular doctor versus a regular site. Health Services Research, Vol. 37, No. 6, 2002, pp. 1509-1529.

[33] Haynes, R. Inequalities in health and health service use: Evidence from the General Household Survey. Social Science and Medicine, Vol. 33, No. 4, 1991, pp. 361-368.

[34] Canadian Institute for Health Information. Hospital beds staffed and in operation, 20152016.In, Ottawa, 2016.

[35] McCord, C., D. Ozgediz, and J. Beard. General Surgical Emergencies.In Essential Surgery: Disease Control Priorities, Third Edition, No. 1, The International Bank for Reconstruction and Development / The World Bank, Washington, D.C., 2015.

[36] Boisjoly, G., and A. El-Geneidy. How to get there? A critical assessment of accessibility objectives and indicators in metropolitan transportation plans. Transport Policy, Vol. 55, 2017, pp. 38-50.

[37] Mattson, J. Transportation, distance, and health care utilization for older adults in rural and small urban areas. Journal of the Transportation Research Board, Vol. 2265, 2011, pp. 192-199. 